\title{
From the Persian Ancient Dramas, Jamm and Simurgh Toward the Modern Military Medicine
}

\author{
Ali Reza Khoshdel ${ }^{1,{ }^{*}}$, Mohammad Hossein Lashkari ${ }^{2}$ \\ 1 Department of Epidemiology, Faculty of Medicine, AJA University of Medical Sciences, Tehran, IR Iran \\ 2 Department of Surgery, Faculty of Medicine, AJA University of Medical Sciences, Tehran, IR Iran \\ *Corresponding author: Ali Reza Khoshdel, P.O.Box:16315-781, Tehran, IR Iran. Tel/Fax: +98-2188337909, E-mail: alikhoshdel@yahoo.com.
}

Received: September 22, 2013; Accepted:September 30, 2013

Keywords: History of Medicine; Persian History; Military Medicine

\section{Introduction}

Military medicine is now a professional and multidisciplinary area in medicine. It includes not only ordinary but also nonconventional aspects of medicine. Military medicine has a long history as old as construction of organized armed force in ancient civilizations. Although the spectrum of this specialty is much different from its past history, its goal is still the maintaining and recovery of health in military population, veterans and their relatives in war and peace.

\section{Historical Background}

Jammshid (Jamm means twin, and Shid means sun) was a religious smart man who attained the spiritual glory, honor and moral known as "Farr (Farrah)" from God and became a saint who ruled for 700 years. He made the first integrated social infrastructures in Persian community, was famous for his skills in medicine and used many herbs and perfumes for treatment of patients. He was the owner of the crystal globe (Jaam-e'-Jamm or the cup of Jammshid) in which he could monitor events around his governance and observe all the seven heavens. He was the one who established "Nourooz" at the beginning of spring (21st of March) which is still the most popular festival among Iranians. However, the history, myths and romance are mixed for that period of Iranian antiquity about Jamm (1).

Medicine has an ancient history in eastern countries including Iran. Avesta (one of the most ancient religious books in Persia, earlier than 600 BC) named Fereidoon (from Jammshid's descent) as the one who won on Zahac with assistance of Kaveh, the blacksmith. According to ancient Iranian literatures, Freidoon (Treata) used knife and fire and experienced several herbal drugs to cure injured soldiers and was known as the first Iranian surgeon. He was the pioneer of the "Saenamargha" school in medicine. This word was used in Persian literature for a symbol of the spirit of medicine (Simurgh). "Simurgh", the mythological bird, was the legend of spiritual aspects of health (Figure 1) in ancient Persian tales $(2,3)$.

According to "Shahnameh" (the most famous epic poem drama in Iranian literature) Simurgh took care of "Zahl" in his habitant, Alborz (the tallest mountain in Iran and the 4th in the world), when he was rejected by his father because of his congenital albinism. Simurgh also helped Zahl's wife, Roodabeh, when she was delivering Rostam (the legend of power and bravery in Persian mythology) (Figure 2). Rostam was a big baby and Roodabeh suffered from dystocia. Then, Simurgh anaesthetized Roodabeh and cut her abdomen to deliver Rostam and used herbs on her wound for rapid healing. Therefore, many archeologists name this kind of surgery as "Rostam-Zaad" instead of Caesarian, since it was firstly described in the above story and assumed being formerly experienced by Persians. Further, Simurgh helped Rostam in his battle with "Esfandiar" and took care and cured his wounds. Simurgh also cured Iranian military soldiers who blinded in this battlefield with an eye drop extracted from the white devil's liver (4). The importance of symbolic figure of Simurgh in Iranian medicine is its spiritual characteristic which, was even interpreted as a symbol of holy Gabriel.

Apart from the fantasy, 3000 years of documented history of Persia recorded the first medical organization in ancient Persian army. Military medical teams were well organized parts of the Persian army and there were also a system for veterinary medicine for war horses in the army. The role of health was appreciated in the armed

Implication for health policy/practice/research/medical education:

Medicine has a long history in Persian culture. The ancient Persian history demonstrates the prominent value of the spiritual aspect of health in medicine. Accordingly, the development and evolution of military medicine in Iran have been significantly influenced by this understanding. This sheds light on our way toward the future of modern military medicine.

Copyright $($ 2013,AJA University of Medical Sciences; Published by Kowsar Corp. This is an open-access article distributed under the terms of the Creative Commons Attribution License, which permits unrestricted use, distribution, and reproduction in any medium, provided the original work is properly cited. 
force and soldiers were trained to care injured persons in the battlefields. Many stone craves in the ancient palace "Persepolis" in southern Iran demonstrate Pomegranate flower as a symbol of health and love in the

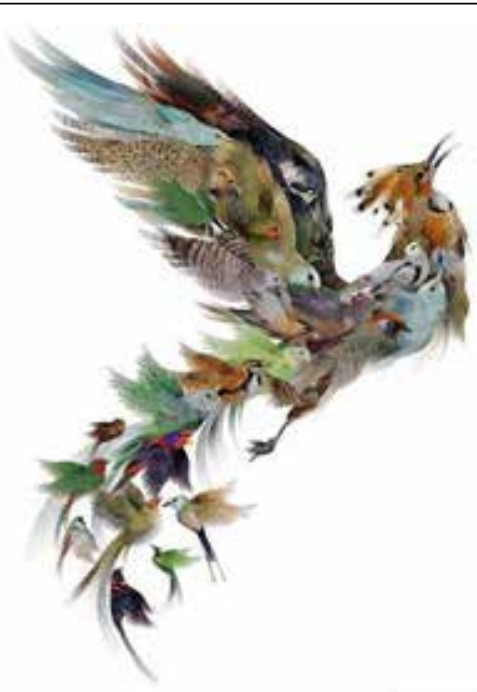

Figure 1. Simurgh (Saena $=$ Physician, Morve $=$ Bird, or a bird as $s i=$ thirty murgh = birds) Is an Iconic Symbol for Medicine in the Ancient Persian Literature With Spiritual Characteristics and Links With Human Soul

Figure 2. The Battle of Rostan (Father) and Sohrab (His Un-Known Son) in the Romance of "Shahnameh", an Ancient Persian Literature.

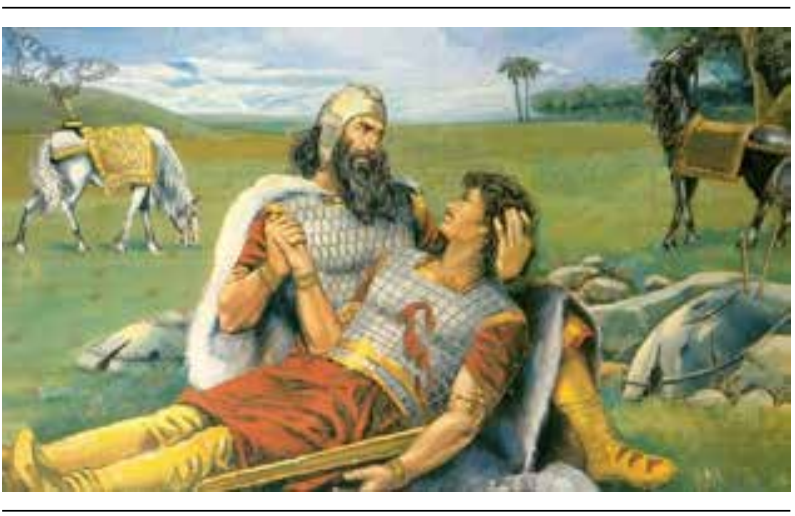

Rostam asked for antidote (Noushdaru) from the king after he knew his son who was injured during the battle. But, the drug arrived after the son passed away.

hand of king and great senior physicians (Moobeds) which were apparently given to soldiers and commanders as a new year gift (Figure 3), and at their deployment to the missions. There were 5 groups of physicians in the army: psychiatrists, physicians for communicable diseases, surgeons, herbal pharmacologists, and life physicians $(1,5,6)$. The latter is a very interesting group due to their role in life style and preventive medicine. Furthermore, military forces had epidemiologists (named as Atrovan) who studied the statistics of the diseases as well as veteri- narians for treatment of war horses.

Physicians had a high rank social position. However, payment for medical services was based on the economic status of people. Therefore, everybody could reach to the physicians. On the other hand, some systems, such as free insurance, were founded for the benefit of the patient. Also, numerous facilities provided for patients in the ancient Persia. This may be because of the effect of religious texts which recommended providing facilities for patients. Pregnant women were paid privilege and had maternity leave with salary. Later, in Sasanid dynasty, people had access to free public medical services and severe disabled patients were exempt of tax (2).

According to historic literature, the first academies for medicine were organized in Iranian army 500 years AC which was followed by pioneer medical school and universities in the Persian lands such as Jondi-Shapur, Samarghand, Teasfoon, Ekbatan, Madaen and Rey, mainly based in military headquarters.

Iranian medicine was substantially improved after Islam's distribution in the region. By the influence of Islam, the leading of medicine transferred from army to libraries, religious schools and mosques. Of paramount importance, Iranian medicine was significantly influenced by Greek, Roman, Indian and Chinese medicine due to its critical geopolitical location as the crossroad between east and west, north and south and also its role as a part of commerce via the Silk Road (2) (Figure 4). The cross talk between these traditional medical cultures, made an enriched Iranian medicine in parallel to appearance of renowned physicians such as Avicena and Rhazes whose books had been used for centuries around the world. As a heritage of this golden age in Iranian medicine, more than 60 editions of Canon (the medical textbook by Avicena) were published in Europe during 1500-1674 as a main reference for humorism. Furthermore, Avicena presented a comprehensive description in sphygmology, urology and ophthalmology which is still used in clinical medicine (6).

\section{Past and Current Paradigms in Medicine}

By the beginning of 16th century, humorism was increasingly criticized and the science of medicine experienced new paradigm that was mainly influenced by the germ theory. This approach changed the disease classification and transformed diagnosis and treatment methodologies. Although the new paradigm improved understanding of human disease and introduced important treatments, it neglected the holistic view of medicine and the spiritual aspects of health. Medical knowledge witnesses black box and Chinese box paradigms as a consequence of concerns about chronic diseases and echo-epidemiology respectively during the past decades. While the human genome project was expected to critically change the view of medicine, by the end of the project, the 
subject looked more sophisticated than it was formerly expected. The multigenic etiology of the majority of

Figure 3. The Pomegranate Flower (Golnar) in the Hand of Mobeds on the Stone Craves in Persepolis.

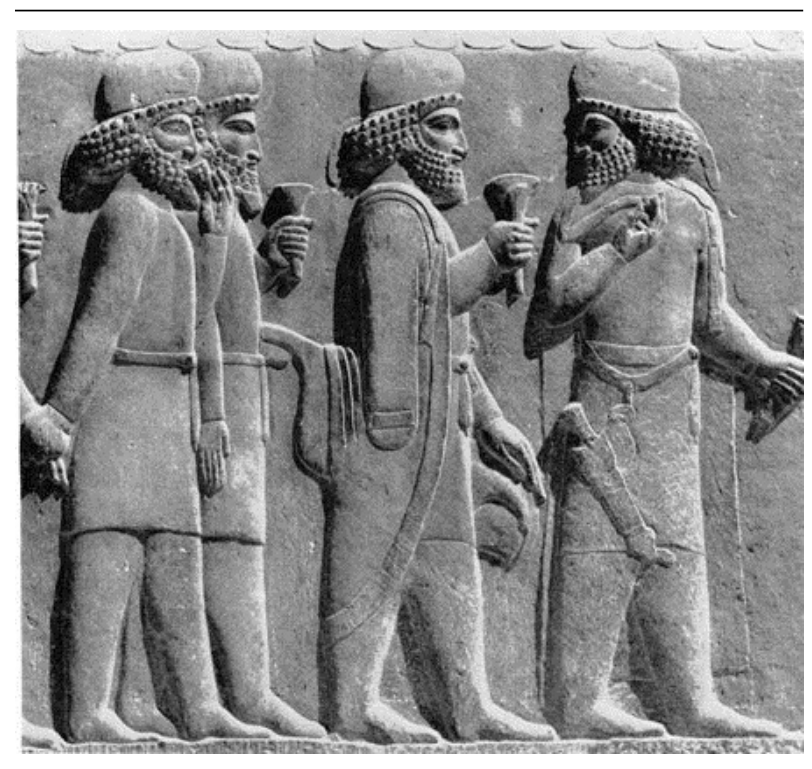

Golnar is a symbol of health and kindness in the ancient Persian culture.

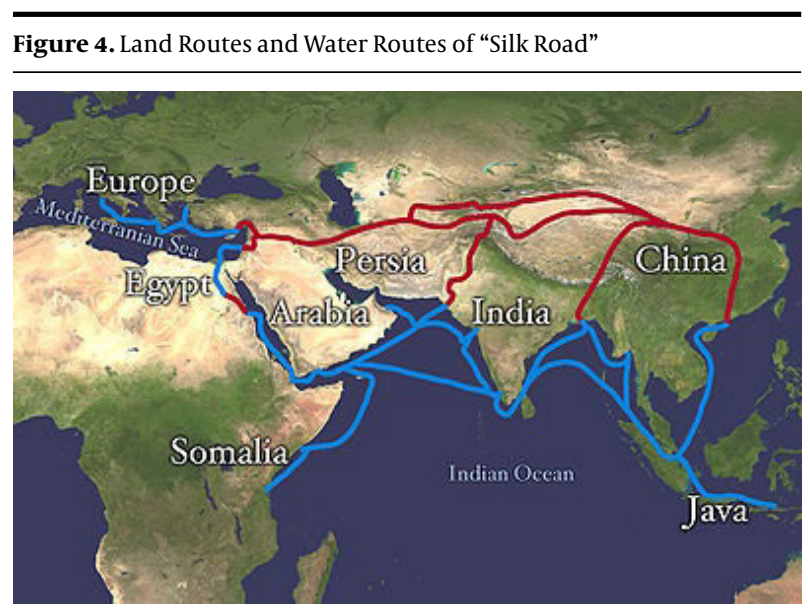

Note the location of Persia as an important region for cross-talk between civilizations of the east and the west in particular for medicine.

diseases and several non-genetic factors that affect the incidence and progression of the diseases leaded to a new understanding of the diseases that has been recently expressed as "diseasomes", a network of several factors influencing the incidence of diseases. This approach demonstrated a new clustering of diseases that suggest potential common pathophysiology within the clusters (7). Of paramount importance, it integrates physical, physiological and epidemiological characters with psychological and spiritual aspects of the diseases (8). Therefore, the new paradigm looks a re-emergence of the old holistic concepts from some aspects. It would cause new classification of the diseases and may introduce new treatment goals for prevention and treatment. Moreover, risk assessment and evidence-based practice have enhanced value in the modern medicine, particularly in military services.

\section{Iranian Military Medicine in the Last Century}

By re-organization of the Iranian modern army in more than 100 years ago, the military medical service was also evolved. That coincided with the golden era of medicine in the west. Therefore, the new military medicine system was greatly influenced by the western medicine. Several Iranian students went to the western universities and returned home after graduation and helped the transition of army from the traditional to modern medicine. One of the critical steps in that period was the origination of "Darolfonoon" (the school of techniques) in a military training field by "Amir Kabir", the prime minister. Medicine and military training were the main disciplines in Darolfonoon and military doctors were the pioneer teachers in the school. Dr Poolak (the Austrian medical practitioner) helped organizing an advanced clinical training in the military hospital which was the first modern hospital in the capital city (Figure 5). Other public and private hospitals began to work within the subsequent years mainly by military medical doctors such as professor "Amir-Aelam" who was among the first presidents of medical school of Tehran University, the first medical university in Iran. The progression of health services inside and outside of army continued during the past decades and as a result of developments in resources, equipment and medical practitioners, a modern system is now actively in charge. Despite substantial developments and a widespread network of hospitals and clinics, military medical services were not mature enough for a real war. However, medical practitioners and paramedics became actively involved in the 1980-1988 war against enemy invasion. The story of Fereidoon and Zahac was repeated and the spirit of Simurgh aroused and medical teams were inspired to defeat the enemies. They scarified themselves for their country's dignity and honor and attained important achievements in novel methods and effective care for the armed force which are now being taught to the next generation of military doctors.

Iranian army has a major contribution in medical education across the country due to the long history of medical services in armed forces and the valuable experience of long-term wartime. The Iranian military medical service not only played a great role in the war but also developed its capacities in important scientific experiences, particularly in traumatology, emergency care, field 
Figure 5. Pioneers of Military Medicine in the First Modern Military Hospital (1912)

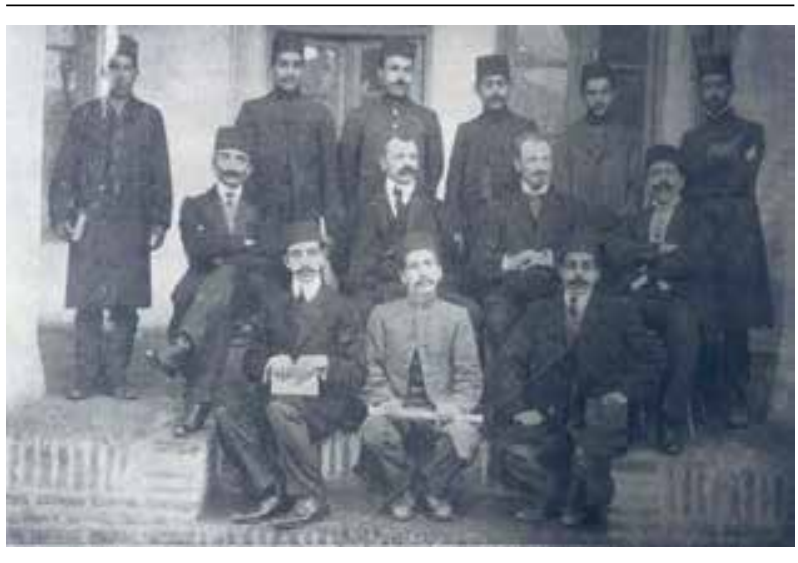

Middle row (From right to left) Dr Hakim-Aezam, Dr Gale', Dr George, Dr Amir-Aelam

epidemiology and rehabilitation. Furthermore, a novel and modern organization has been developed to cope with the wartime requirements. The system has also contributed in humanitarian aids inside and outside the country during natural disasters (Figure 6). Consequently, a multi-potential system has been strongly structured and there are tens of active military hospitals across the country as well as several research institutes and education centers for military medicine now. However, armed forces face new challenges and the medical service must follow the new trends in modern medicine to be able to answer the new desires.

\section{Future Strategies in Military Medicine}

In parallel to the changing nature of battlefields, the military medical doctrine and strategies ought to change to preserve its efficiency. While the main goal of military medicine is maintaining and improving health and recovery from injuries and diseases in armed force personnel, the changing epidemiology of the risk factors and casualties as well as the modifying medical technologies make a revision for the health services inevitable. On the other hand, with increasing life expectancy of veterans, the role of geriatric medicine is becoming more important in the military health services (9).

Moving toward lighter weight forces, which is described as "early in, early out" concept, is now a generally accepted strategy for any armed forces. Besides, battlefields are high-tech and soldiers are rather equipped than armed. The distribution of forces is now different and global international contribution is expected (10). Moreover, the epidemiology of emerging and re-emerging diseases has had a major impact on this population. Therefore, the current global military medicine priorities include
Figure 6. Air-Born Aid in Natural Disaster (A) and During War (B) by the Iranian Armed Forces

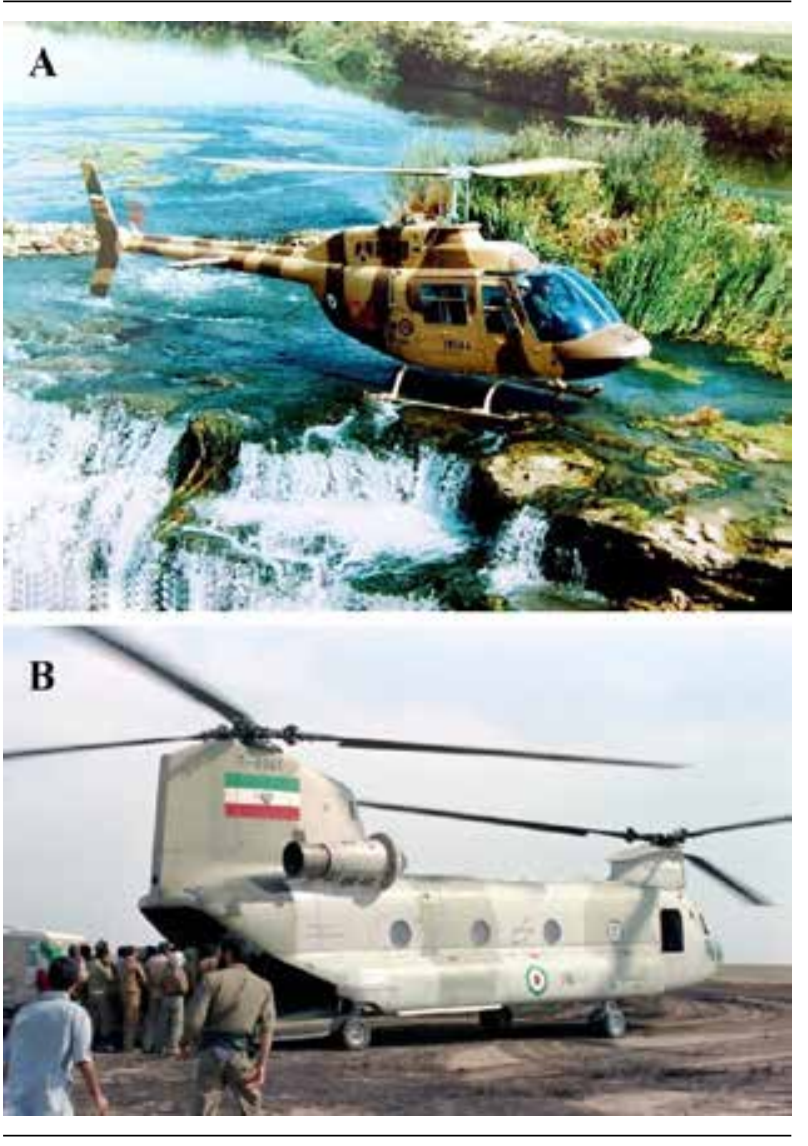

Sources of photos are http://jomhourieslami.blogfa.com and www. mashreghnews.ir respectively.

better communication, biomedical research in particular about biologic threat, mobile hospital and flying ICUs (11). Also, developments in artificial blood, polyvalent singledose vaccines by novel nano-biotechnology methods and genomic-based therapeutics are critically required in the future army. In addition, modern military medicine needs an advanced disease surveillance system, focusing on emerging and re-emerging diseases as well as health geomatics. More importantly, a global collaboration is needed for a significant improvement in military medical services via a modern reliable communication system.

Finally, with rapid progression in space and submarine exploration, aerospace and diving medicine requires a balanced improvement in the military health system.

\section{Conclusions}

Military medicine has significant footsteps in Persian ancient historical culture which is a combination of facts, myths and dramas. This is related to eastern believes about various physical, psychological, social and 
spiritual aspects of health for any single armed force. Based on this holistic view, the modern military medicine is expected to answer the challenges of the future battlefield as well as the changing face of disease epidemiology in order to guarantee all aspects of health for military personnel.

\section{Authors' Contribution}

Both authors were actively contributed in literature review and manuscript preparation.

\section{References}

1. Dastmard F, Hemmati S. An overview of medicine science in Shahnameh. J Basic Applied Sci Res Mil Vet Health. 2013;3(1):1117-23.

2. Yarmohammadi H, Mojahedian MM, Zargaran A. Medicine and Economy in Ancient Persia. Res His Med. 2012;1(3):91-5.

3. Yousefzadeh N. Symbolic world of dream in Kushnameh.J Am Sci. 2011;7(10):84-91.
4. Shahnameh.[cited September the 26th]; Available from: http:// en.wikipedia.org/wiki/The_Epic_of_Kings.

5. Sigerist HE. A history of Medicine. USA:Oxford University Press; 1987.

6. Moosavi J. The place of avicenna in the history of medicine. Avicenna J Med Biotechnol.2009;1(1):3-8.

7. Barabasi AL. Network medicine-from obesity to the "diseasome". N Engl J Med. 2007;357(4):404-7.

8. Midic U, Oldfield CJ, Dunker AK, Obradovic Z, Uversky VN. Unfoldomics of human genetic diseases: illustrative examples of ordered and intrinsically disordered members of the human diseasome. Protein Pept Lett. 2009;16(12):1533-47.

9. Lennon RP, Saguil A, Seehusen DA, Reamy BV, Stephens MB. The military health system: a community of solutions for medical education, health care delivery, and public health. J Am Board Fam Med. 2013;26(3):264-70.

10. Salisbury D, English A. Prognosis 2020: A military Medical Strategy for the Canadian Forces 2012. Canada Mil J. 2013;Summer:45-55.

11. Coughlin SC, McNeil RB, Provenzale DT, Dursa EK, Thomas CM. Methos issues in epidemiological studies of medically unxplained synptome-based conditions in veterans. J Mil Vet Health. 2013;21(2):4-11. 